\title{
A LIBERDADE É UMA LUTA CONSTANTE
}

Resenha: Fernando de Sá Moreira ${ }^{1}$

Universidade Federal Fluminense (UFF)

(i) https://orcid.org/0000-0002-9545-435X

E-mail: fernandosm@id.uff.br

\section{DAVIS, Angela. A liberdade é uma luta constante. Organização de Frank Barat; tradução de Heci Regina Candiani. 1. ed. São Paulo: Boitempo, 2018. 144 p.}

Chega-nos às mãos no Brasil uma das produções mais recentes da filósofa estadunidense Angela Yvonne Davis, intitulada "A liberdade é uma luta constante". Trata-se de um pequeno livro organizado pelo ativista Frank Barat, que reúne dez entrevistas, discursos e conferências ministradas pela filósofa entre os anos de 2013 e 2015. A celeridade com que a obra chega ao Brasil é uma boa indicação da importância que a autora tem recebido nos mais diversos meios de estudo e luta em nossas terras. O livro foi lançado originalmente em 2016 pela editora Haymarket de Chicago $^{2}$ e apenas cerca de dois anos depois já está disponível para os leitores brasileiros em boa tradução de Heci Regina Candiani.

A título de comparação, aquela que é talvez a obra mais célebre de Angela Davis, a mundialmente conhecida Mulheres, raça e classe $^{3}$, publicada originalmente em 1981, só ganhou uma edição formal no Brasil em 2016. Tanto quanto me foi possível averiguar, há apenas uma versão anterior desse livro em português, atribuída à "Plataforma Gueto", um coletivo negro de Portugal. A iniciativa de tradução livre da clássica obra de Davis, segundo a própria Plataforma Gueto, foi empreendida por 17 mulheres negras (DAVIS, 2013, p. 3). Todavia, mesmo levando em conta a versão portuguesa, vale a pena frisar que mais de três décadas separam a publicação original do texto de Angela Davis e sua chegada ao público lusófono.

No caso da edição brasileira, a tradutora é doutora em Ciências Sociais e já realizou também duas outras traduções de obras de Angela Davis, lançadas pela editora Boitempo no Brasil: a já mencionada Mulheres, raça e classe e também Mulheres, cultura e política, ${ }^{4}$ esta última original de 1990 e lançada em 2017 em português. A edição brasileira de $A$ liberdade é uma luta constante conta com uma introdução de autoria de Frank Barat, uma prefácio do também filósofo negro norte-

\footnotetext{
1 Doutor em Filosofia pela Pontifícia Universidade Católica do Paraná (PUC/PR), Curitiba - PR, Brasil. Professor da Universidade Federal Fluminense (UFF), Niterói - RJ, Brasil.

${ }^{2} \mathrm{O}$ nome da publicação original contém também um subtítulo, que não foi incluído na versão brasileira, "Freedom is a Constant Struggle: Ferguson, Palestine, and the Foundations of a Movement" ("Liberdade é uma Luta Constante: Ferguson, Palestina e as Fundações de um Movimento", em uma tradução literal).

3"Women, Race \& Class", no título original em inglês.

4"Women, Culture \& Politics", no título original em inglês.
}

DAVIS, Angela. A liberdade é uma luta constante. Organização de Frank Barat; tradução de Heci Regina Candiani. 1. ed. São Paulo: Boitempo, 2018. 144 p. Resenha por Fernando de Sá Moreira. Griot : Revista de

Filosofia, Amargosa - BA, v.18, n.2, p.480-485, dezembro, 2018. 
americano Cornel West, um prefácio à edição brasileira de Angela Figueiredo, além de textos de orelha da escritora Conceição Evaristo.

A autora, Angela Davis, é uma das mais influentes intelectuais ativistas contemporâneas. Nascida em 1944, esteve presente na luta pelos direitos civis nos EUA da década de 1960 e 1970. Ainda nesse mesmo período, depois de concluir sua formação entre os EUA e a Europa (em especial a Alemanha), a filósofa iniciou sua carreira como professora universitária. Esse é precisamente um aspecto de sua biografia, cujo sentido eu gostaria explorar muito rapidamente ao lado de sua obra teórica: ainda que já estivesse trilhando uma carreira acadêmica, ela não abriu mão da luta social e política, pois ela não enxerga sua vida acadêmica apartada do ativismo social. Pelo contrário, sua filosofia é produto de seus engajamentos teóricos e também de seus engajamentos político-sociais, simultânea e talvez indissoluvelmente.

Pode-se dizer, portanto, que a filosofia política de Angela Davis não a constitui como uma filósofa $e$ ativista, senão como uma filósofa-ativista. Isso tem um impacto crucial também na forma como ela enxerga sua própria autoria, originalidade e celebridade. No que diz respeito a grande visibilidade que certos indivíduos, inclusive ela mesma, obtêm ao lutar de forma mais ou menos bem sucedida contra estruturas de opressão, ela não cansa de enfatizar a importância dos movimentos coletivos que suportam essas figuras de destaque. Nesse sentido, ela afirma sobre Martin Luther King: "[ele] foi um grande homem, mas em minha opinião a grandeza dele residia justamente no fato de que aprendeu com o movimento coletivo" (DAVIS, 2018, p. 110). Em outro momento, falando de modo mais geral, ela afirma:

\footnotetext{
Muitas vezes, aprendemos com os movimentos que acontecem na base e devemos ter muito cuidado para não pressupor que essas ideias nos pertencem enquanto indivíduos ou, pelo menos, enquanto personalidade com maior visibilidade; temos de reconhecer que aprendemos com isso e que queremos compartilhar tais ideias. É esse papel que me veria representando.
}

Ela se posiciona então contrariamente à ideia de que seu pensamento é fruto única e exclusivamente de sua genialidade. Ao invés disso, poderíamos dizer que seus conceitos e reflexões são certamente o resultado de suas ponderações individuais sim, mas que isso não significa que se deva ignorar que são também - e talvez em seus aspectos mais importantes - frutos das reflexões coletivas dos movimentos sociais, das lutas pelos direitos humanos, dos encontros de coletividades criadoras e combatentes nas quais Angela Davis se engaja. Devemos pensar sua pena e sua autoria como a afluência de muitas vozes.

Para Davis, o sentido mesmo de sua visibilidade deve também reconhecer seu lugar de fala ${ }^{5}$ e as coletividades que dão sentido a essa visibilidade:

\footnotetext{
${ }^{5}$ Sobre o conceito de lugar de fala, confira RIBEIRO, 2017. Sobre o reconhecimento de Davis a respeito de seus aprendizados, seu lugar de fala como feminista negra norte-americana em relação às mulheres/feministas negras brasileiras, confira DAVIS, 2017b e 2017c. Sobre as intelectuais negras brasileiras, ela menciona, entre outras, Beatriz Nascimento, Lélia Gonzalez, Luiza Bairros, Carolina Maria de Jesus.
}

DAVIS, Angela. A liberdade é uma luta constante. Organização de Frank Barat; tradução de Heci Regina Candiani. 1. ed. São Paulo: Boitempo, 2018. 144 p. Resenha por Fernando de Sá Moreira. Griot : Revista de 
Com frequências, as pessoas me perguntam como eu gostaria de ser lembrada. Minha resposta é que realmente não estou tão preocupada com o modo como as pessoas se lembrarão de mim enquanto pessoa. O que eu quero que as pessoas recordem é o fato de que o movimento que exigiu minha liberdade ${ }^{6}$ triunfou. (DAVIS, 2018, p. 120).

Em geral, os temas trabalhados em $A$ liberdade é uma luta constante giram em torno dos engajamentos mais recentes de Davis, além de uma análise de lutas contra o capitalismo global. Por exemplo, a autora debate o sentido de se sustentar um posicionamento político e ativo em sociedades como as nossas. Ela passa também a limpo elementos de sua própria história de luta e dos desenvolvimentos dos movimentos sociais nos EUA e no mundo, em especial desde meados do século XX. Também trabalha com o sentido de eventos sociais e políticos recentes, sobretudo nos EUA, como a eleição e presidência de Barack Obama, ${ }^{7}$ as manifestações de Ferguson, ${ }^{8}$ os movimentos Black Lives Matter ${ }^{9}$ Occupy ${ }^{10}$ etc.

A filósofa negra chama atenção também para as interconexões de luta transnacionais. $O$ exemplo mais evidente e presente no livro de Davis é a questão da Palestina. É certo que o foco nessa questão pode ser influência do organizador Frank Barat, um conhecido ativista pró-Palestina. Contudo, é importante observar também que, em um contexto global como o nosso, as lutas sociais estão de fato profundamente conectadas, tanto pelo lado daquele que oprime, quanto pelo lado do oprimido.

A autora nos fornece um bom exemplo disso quando descortina de forma ousada, que há entrecruzamentos entre um Estado punitivista e carcerário nos EUA, a lógica de ocupação, controle e repressão de protestos por parte do Estado de Israel em territórios palestinos e interesses de grandes corporações do capitalismo global no setor de segurança, como a G4S (e.g. DAVIS, 2018, p. 22). Não obstante é importante não esquecer também que não somente as opressões se interligam, mas também as

\footnotetext{
${ }^{6} \mathrm{Na}$ década de 1970, Angela Davis foi dada como foragida, capturada e presa. Sua acusação recaía sobre um suposto envolvimento dela em uma tentativa frustrada de libertação de um grupo de prisioneiros conhecidos como os Soledad Brothers. O evento ocorrido em 7 de agosto de 1970 acabou com a morte de 4 pessoas, incluindo um juiz. Davis chegou a ser incluída na lista dos 10 fugitivos mais procurados pelo FBI. Sua prisão desencadeou uma onda internacional de manifestações em defesa de sua liberdade. Ela foi posteriormente considerada inocente de todas as acusações.

7Obama governou os EUA durante dois mandatos entre janeiro de 2009 e janeiro de 2017. Ele é reconhecido como o primeiro presidente negro estadunidense, um fato representativo para a comunidade negra do país, mas que também recebeu atenção global. Para Davis, contudo, apesar de portar algumas pautas progressistas, é preciso considerar que Obama não foi nenhum redentor do racismo norte-americano, não deu - e nem poderia ter dado início a era pós-racial nos EUA (e.g. DAVIS, 2018, p. 77). Vale lembrar que o livro de Davis reúne reflexões entre 2013 e 2015, tendo sido lançado em 2016. Consequentemente, ele não debate as ações do atual governo dos EUA, iniciado com a tomada de posse do polêmico Donald Trump em 2017. Alguns apontamentos a esse respeito podem ser encontrados em uma palestra que ela ministrou recentemente no Brasil (DAVIS, 2017c).

${ }^{8}$ As entrevistas e conferências foram concedidas justamente em meio a uma onda de protestos antirracistas que tomaram conta dos EUA, cujo epicentro foi justamente a cidade de Ferguson no estado do Missouri. A situação foi desencadeada após a morte, com indícios de assassinato, do adolescente negro e desarmado Michael Brown, perpetrada pelo policial branco Darren Wilson. Diversas manifestações ocorreram a partir de então, as quais foram respondidas pela política de forma muitas vezes violenta e militarizada.

${ }^{9}$ Organização internacional de combate à violência estatal contra populações negras. Sua origem data a 2013, após a absolvição de um segurança branco chamado George Zimmerman acusado de assassinar em 2012 o adolescente negro Trayvon Martin no estado americano da Flórida.

${ }^{10}$ Movimento de ocupação e protesto inicialmente deflagrado em 2011 no setor financeiro de Nova Iorque. Gradativamente surgiram várias manifestações Occupy ao redor do mundo.
}

DAVIS, Angela. A liberdade é uma luta constante. Organização de Frank Barat; tradução de Heci Regina Candiani. 1. ed. São Paulo: Boitempo, 2018. 144 p. Resenha por Fernando de Sá Moreira. Griot : Revista de 
resistências estão conectadas e podem se conectar ainda mais. Um dos exemplos trabalhados pela filósofa em seu livro é a troca de informações entre manifestantes em Ferguson, reprimidos duramente por uma polícia que adotava treinamento e táticas de Israel, e ativistas palestinos por meio do aplicativo de microblogging Twitter (e.g. DAVIS, 2018, p. 51). Ao perceber que as forças policiais atuavam contra manifestantes de forma altamente militarizada em Ferguson e usando equipamentos de dispersão idênticos aos empregados contra palestinos pelo aparato repressivo israelense, os ativistas palestinos - mais experientes - trocaram informações com os ativistas em Ferguson sobre as melhores maneiras de se proteger.

O olhar simultâneo para a produção mais antiga e mais recente de Davis pode certamente nos fornecer algumas percepções instigantes. Penso aqui principalmente no contraste entre Mulheres, raça e classe e A liberdade é uma luta constante. Enquanto no clássico de 1981 estávamos já em contato com o resultado de uma reflexão filosófica, social e política extremamente fértil, nos textos mais recentes temos a oportunidade de encontrar algumas das continuidades e os frutos mais maduros da reflexão da pensadora. É difícil dizer que tenha havido uma ruptura entre esses dois momentos da produção de Davis. Todavia, é também difícil sustentar que sua análise não teria passado por modificações e desdobramentos sensíveis.

Um exemplo notável disso pode ser encontrado na importante noção de interseccionalidade, cuja centralidade na obra da filósofa estadunidense é mundialmente reconhecida. Essa noção passa por uma impressionante expansão entre 1981 e 2016. Em Mulheres, raça e classe, Davis trabalha sobre certos momentos da história dos Estados Unidos, principalmente entre os séculos XIX e XX. Seu foco recai majoritariamente sobre o caso das mulheres negras norte-americanas. Um de seus objetivos principais consiste em trazer à tona a necessidade premente por análises que abordem as condições sociais de grupos oprimidos a partir de múltiplas categorias. Na década de 1980, o trabalho de Davis concentrou-se basicamente em 3 categorias fundamentais: sexo, raça e classe social.

Ao analisar a trajetória de mulheres negras devemos perceber que elas muitas vezes encontram-se triplamente oprimidas. Levando-se em consideração o seu sexo, elas sofrem opressões por serem mulheres e viverem em uma sociedade profundamente machista. Levando-se em consideração seu pertencimento racial, a discriminação chega a elas por serem negras. Considerando a organização capitalista da sociedade e que a mulher negra teve para si relegado majoritariamente o trabalho doméstico e os piores postos do trabalho formal, elas amargam também uma profunda exploração de sua atividade laboral por serem trabalhadoras rurais, operárias e trabalhadoras domésticas. Vale observar que a restrição das mulheres negras a certas condições de trabalho não é um mero acaso, mas uma articulação dos setores exploradores de sua condição interseccional de mulher negra.

O conceito de interseccionalidade opera então em um duplo registro: (1) em um campo analítico, ele serve para permitir que entendamos como uma determinada sociedade é formada de modo a articular explorações, aproveitando-se da interseção de diversas categorias que transpassam um indivíduo ou um grupo social; (2) em um campo propositivo, ele serve para chamar a atenção dos movimentos emancipatórios para a necessidade de promover lutas que considerem as interseções entre as

DAVIS, Angela. A liberdade é uma luta constante. Organização de Frank Barat; tradução de Heci Regina Candiani. 1. ed. São Paulo: Boitempo, 2018. 144 p. Resenha por Fernando de Sá Moreira. Griot : Revista de 
categorias que se encontram em um indivíduo ou grupo e também entre as lutas de indivíduos de categorias diferentes.

Agora, passadas mais de 3 décadas, a fala de Angela Davis nos soa igualmente penetrante e atual. Sua concepção de interseccionalidade passa por uma notável expansão. Ainda é possível divisar facilmente as categorias gênero, raça e classe em A liberdade é uma luta constante, entretanto encontramos ao lado delas diversos outros vieses de análise. Podemos mencionar aqui, por exemplo, geração, capacidade, sexualidade, nacionalidade, religiosidade etc (DAVIS, 2018, p. 50-51 e passim). O ponto de vista atual da filósofa parece também retomar e transformar algumas de suas categorias mais antigas. A categoria gênero, por exemplo, passa a considerar de modo mais explícito a transexualidade. O feminismo de Angela Davis advoga pela necessidade de se pensar as mulheres trans plenamente como mulheres (e.g. DAVIS, 2018, p. 93). Ela promove também intersecções entre a ideia de raça, etnia e religiosidade, ao afirmar, por exemplo, que a islamofobia é hoje uma forma de racismo insidiosamente lucrativa, tanto nos EUA quanto no Oriente Médio a partir, por exemplo, do emprego de um complexo industrial-prisional ${ }^{11} \mathrm{e}$ de vigilância tanto contra populações negras quanto contra populações muçulmanas. Como Davis afirma em determinado momento (2018, p. 56): "Não faz sentido imaginar a erradicação do racismo contra as pessoas negras sem erradicar o racismo contra as pessoas muçulmanas".

Enfim, o que pode significar o lançamento no Brasil de $A$ liberdade é uma luta constante? Acredito que essa pergunta só pode encontrar uma resposta satisfatória se soubermos levar em conta mais do que apenas o livro em si. O livro em si, como uma coletânea de materiais independentes e relativamente curtos, frequentemente nos deixa com a sensação de que uma ou outra ideia poderia ser mais longamente desenvolvida, uma ou outra análise não foi suficientemente desdobrada etc. Essa é uma consequência inevitável de coletâneas como essa. Com efeito, o sentido desse livro se encontra além, mais propriamente nas profundas conexões que podemos traçar com a trajetória da autora, com a trajetória de inúmeras pessoas oprimidas ao redor do mundo, em especial as negras, com as lutas que, atravessando Angela Davis, permitiram que certas ideias poderosas nos chegassem por sua pena, nas interseções entre Davis e o Brasil.

O livro tem a característica de servir tanto como um ponto de entrada na filosofia de Angela Davis quanto como um caminho de aprofundamento nela e nos problemas que ela levanta. Se não se pode dizer talvez que as reflexões da autora são a resposta definitiva para os problemas do Brasil, é o caso - assim me parece - de reconhecer pensamento dessa grande feminista negra como um caminho potente. Mais do que talvez apenas mais um caminho em meio a tantos outros, Davis parece construir uma abordagem visceral para os problemas globais de nosso tempo, incluindo casos particulares da realidade brasileira. Mas, além disso, ela acaba por nos convidar à reflexão, ela nos convoca a construir um pensamento emancipador em conjunto. Ela nos lembra que "a liberdade é uma luta constante", sem nos deixar esquecer que a liberdade é também uma luta coletiva, global e sistêmica.

${ }^{11}$ Conexões entre o racismo e o encarceramento foram e têm sido tecidas também com alguma frequência pelos intelectuais brasileiros. Dois exemplos significativos podem ser encontrados nas análises de Abdias Nascimento (2017) e Marielle Franco (2014).

DAVIS, Angela. A liberdade é uma luta constante. Organização de Frank Barat; tradução de Heci Regina Candiani. 1. ed. São Paulo: Boitempo, 2018. 144 p. Resenha por Fernando de Sá Moreira. Griot : Revista de 


\section{Referências Adicionais}

“BLACK LIVES Matter". Disponível em < https://blacklivesmatter.com/>. Acesso em 04/07/2018.

DAVIS, A. (2016). “A liberdade é uma luta constante". Organização de Frank Barat e tradução de Heci regina Candiani. 1. ed. São Paulo: Boitempo, 2018.

. (1981). "Mulher, raça e classe". Tradução livre de Plataforma Gueto. 2013.

Disponível em <https://plataformagueto.files.wordpress.com/2013/06/mulheres-

rac3a7a-e-classe.pdf $>$. Acesso em 03/07/2018.

. (1990). "Mulheres, cultura e política". Tradução de Heci Regina Candiani, 1.

ed. Edição Kindle. São Paulo: Boitempo, 2017a.

. (1981). "Mulheres, raça e classe". Tradução de Heci Regina Candiani. 1. ed.

São Paulo: Boitempo, 2016.

"Angela Davis no Brasil // Curso: feminismo negro descolonial nas

Américas". Disponibilizado pelo canal TV Boitempo na plataforma on-line Youtube em 18 de julho 2017b. Disponível em

<https://www.youtube.com/watch?v=Az3uvwz0P1M>. Acesso em 04/07/2018.

. "Angela Davis, no Brasil / BAHIA, ao vivo na TVE". Disponibilizado por

Ecolink Brasil na plataforma on-line Youtube em 26 de julho de 2017c. Disponível

$\mathrm{em}<\mathrm{https}$ ://www.youtube.com/watch?v=1ddyxOQ45jI>. Acesso em 05/07/2018.

FRANCO, M. "UPP - A redução da favela a três letras: uma análise da política de segurança pública do Estado do Rio de Janeiro". Dissertação (Mestrado em Administração) - Universidade Federal Fluminense. Niterói, 2014.

NASCIMENTO, A. (1978). “O genocídio do negro brasileiro: processo de um racismo mascarado". 1. reimpressão da 2. edição. São Paulo: Perspectiva, 2017.

RIBEIRO, D. “O que é: lugar de fala?”. Belo Horizonte: Letramento/Justificando, 2017.

Autor(a) para correspondência: Fernando de Sá Moreira, Universidade Federal Fluminense, Centro de Estudos Sociais Aplicados, Rua Professor Marcos Valdemar Freitas Reis, s/n, Faculdade de Educação, Campus do Gragoatá, São Domingos, CEP 84269090, Niterói - RJ, Brasil. fernandosm@id.uff.br

DAVIS, Angela. A liberdade é uma luta constante. Organização de Frank Barat; tradução de Heci Regina Candiani. 1. ed. São Paulo: Boitempo, 2018. 144 p. Resenha por Fernando de Sá Moreira. Griot : Revista de 